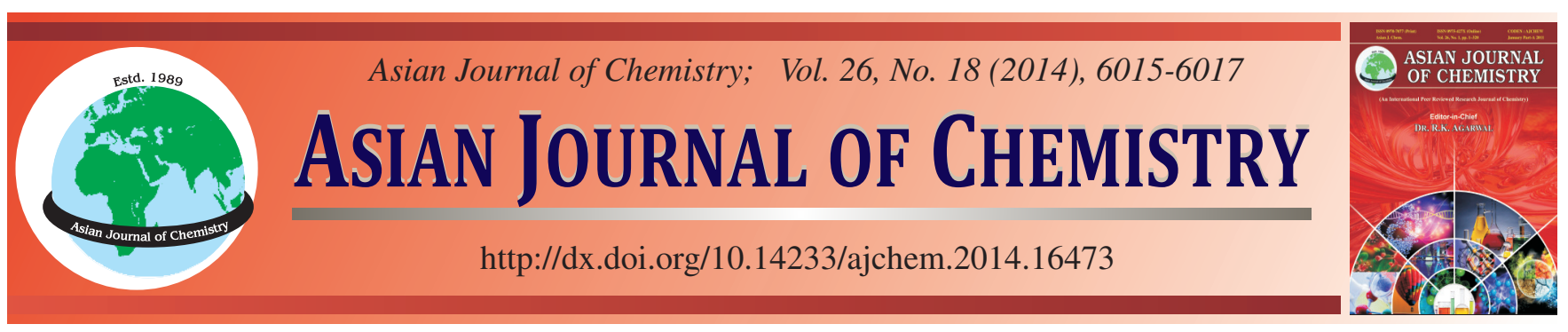

\title{
Antibacterial Properties of Nano-Layered Au, Ag and Al Film Coatings on Flexible Organic Substrates
}

\author{
Zerrin Pat ${ }^{1, *}$, ÖZlem SANCI ${ }^{2}$, HÜSEYin YÜKSEL ${ }^{1}$ and SuAt PAT ${ }^{3}$
}

${ }^{1}$ Department of Chemistry, Art \& Science Faculty, Bilecik Seyh Edebali University, Bilecik, Turkey

${ }^{2}$ Department of Microbiology, Bozüyük State Hospital, Bilecik, Turkey

${ }^{3}$ Departments of Physics, Art \& Science Faculty, Eskisehir Osmangazi University, Eskisehir, Turkey

*Corresponding author: Tel/Fax: +90 228 2141483; E-mail: zerrin.pat@bilecik.edu.tr

The antibacterial properties of a surface are important for the health industry. Gold, silver and aluminium nano-layers were coated using a metal plasma vacuum arc on flexible organic substrates. The antibacterial properties of the coated nano-layered metal films were examined using $E$. coli (ATCC 25922$)$ bacteria. The contact time of the bacteria solutions $\left(10^{9} \mathrm{CFU} / \mathrm{mL}\right)$ to the nano-layered metal coatings was adjusted to $3 \mathrm{~h}$ in the experimental procedures. The antibacterial properties of the coated and uncoated samples were determined after $24 \mathrm{~h}$. The obtained results show that the antibacterial properties of the nano-layered metal film coatings on flexible organic substrates were improved. The antibacterial effect is determined as $\mathrm{Ag}>\mathrm{Au}>\mathrm{Al}$. In addition, the surface roughness and the surface free energies of the coated samples were determined. The produced coatings showed the antibacterial property.

Keywords: Thin film, Antibacterial property, Surface morphology, Surface free energy.

\section{INTRODUCTION}

Nano-antibacterial materials have attracted great interest because many pathogenic bacteria are potential threats of disease dissemination. Moreover, many strains of bacteria have developed a multidrug-resistant (MDR) and versatile adaptive mechanism to colonize surfaces. Antibacterial materials can be used in various fields, such as biomedical, food preserve, textile and electronic materials ${ }^{1-9}$.

Escherichia coli is a gram-negative bacterium, can cause infections, such as urinary tract infections, meningitis and diarrheal diseases ${ }^{10}$. Thus, inhibition of the proliferation of this bacterium is very important for human health.

A metal used in antibacterial applications is gold. Gold is nontoxic, polyvalent and has photothermal effects. It also shows versatility for surface modification ${ }^{7,11-16}$. Another metal used is aluminum, which is generally used in food industries. In this study, we investigated the antibacterial properties of nano-structured $\mathrm{Au}, \mathrm{Ag}$ and $\mathrm{Al}$ films coated on flexible organic substrate surfaces.

Nano-layers and thin films of materials can be produced using various methods, including sol gel, chemical vapor deposition, physical vapor deposition and RF/DC sputtering ${ }^{5,6}$. The advantages and disadvantages of these methods have been presented in the literature. In this study, the arc coating method was used to produce nano-layered films from metal plasma. The nano-layered coated surface in the metal plasma vacuum arc is homogeneous, flat, compact and nano-structured ${ }^{17-19}$.

Currently, flexible organic substrates are used in many technological applications. For example, they are most commonly used in device applications with functional thin films. Because the melting points of organics are notably low, these plastic materials cannot be sterilized using commercial and traditional methods. These substrates are also chemically active. To obtain a chemically inert surface, substrates should be coated with chemically inert metals. Moreover, these coating materials must be harmless. Hence, flexible organic substrates have been coated with nano-layered metal films, which are antibacterial and chemically inert.

In this study, flexible organic substrates were coated with nano-structured $\mathrm{Ag}, \mathrm{Au}$ and Al pure metal using vacuum arc coating. In particular, all coated flexible organic substrates were prepared to be transparent. The surfaces of the coated thin metal films were characterized using atomic force microscopy (AFM). The surfaces are flat, homogeneous and nano-structured. Atomic force microscopy was used for surface imaging and roughness measurement of the surface morphology. Attension Theta Lite was used to measure the surface contact angles of the prepared samples. The antibacterial activities of the nano-layered $\mathrm{Au}, \mathrm{Ag}$ and $\mathrm{Al}$ films 
that were deposited on flexible organic substrates were investigated.

\section{EXPERIMENTAL}

Flexible organic substrate samples were coated with pure gold, silver and aluminum metal slug using plasma arc technology, which produced homogeneous, uniformly coated samples with nano-structured properties. The flexible organic substrate samples were coated in high vacuum conditions $\left(10^{-6}\right.$ Torr $)$. The coated materials are notably pure. The thicknesses of the coated materials are less than approximately $100 \mathrm{~nm}$ to ensure that the samples are transparent.

Antibacterial test: The antibacterial properties against E. coli (ATCC 25922) bacteria of the coated thin metal films ( $\mathrm{Au}, \mathrm{Ag}$ and $\mathrm{Al}$ ) on flexible organic substrates were tested. The bacteria were cultured on Eosin methylene blue agar (EMB agar) at $37{ }^{\circ} \mathrm{C}$ for $24 \mathrm{~h}$. Then, in the prepared test bacterial suspension, microorganisms were added until the concentration reached approximately $10^{9}$ colony forming units per $\mathrm{mL}$ (CFU/ $\mathrm{mL})$. The coated and uncoated samples were sterilized with $96 \%$ ethanol; afterward, the surface was cleaned with sterilized de-ionized water. After drying the samples completely, 100 $\mu \mathrm{L}$ of the test bacterial suspension was spread over $20 \times 20$ $\mathrm{mm}$ on the surfaces in sterile petri dishes in sterile conditions. All petri dishes were incubated at $37^{\circ} \mathrm{C}$ for $160 \mathrm{~min}$. To retrieve the bacteria from the surfaces after the $160 \mathrm{~min}$, all samples were washed with $10 \mathrm{~mL}$ of sterile phosphate buffered saline (PBS) (pH 7.1) and shaken at $100 \mathrm{rpm}$ for $3 \mathrm{~min}$. Afterwards, $100 \mu \mathrm{L}$ of each bacteria suspension in PBS was used to determine the number of surviving bacteria after incubation on EMB agar plates for $24 \mathrm{~h}$ at $37^{\circ} \mathrm{C}$. The number of bacterial colonies was counted after the incubation time ${ }^{20}$.

\section{RESULTS AND DISCUSSION}

Because the surface is compact, the ion energies of the coating method used was high compared with chemical methods. All coatings on flexible organic substrate samples in this study were realized with metallic ions. In addition, a buffer gas was not required. Thus, contaminants were not detected for this coating process. In general, loaded metallic coatings decompose quickly with environmental effects. In particular, coated surfaces are quickly decomposed by ethanol at the surface during the sample preparation step. Our samples were sterilized with $96 \%$ ethanol before washing them with sterile distilled water. Any decomposition at the surface was not detected.

Surface morphologies and surface free energies are some of the most important parameters of bacterium attachment to surfaces $^{5}$. When the roughness increases, the surface area is increased. Hence, more adhesive force can be generated at a rough surface ${ }^{21}$. The roughness values can be more accurately measured using AFM for nanostructured coatings. An optical tensiometer was used to measure the surface free energy of the coated surfaces.

Gold, silver and aluminium thin layers were coated on flexible organic substrates using plasma arc technologies. In particular, all samples were coated as transparent. To realize a transparent thickness, the coating layers are approximately 100 $\mathrm{nm}$ for all metals. Surface images of the $\mathrm{Au}, \mathrm{Ag}$ and $\mathrm{Al}$ layers were obtained using AFM and the obtained 3D images are shown in Fig. 1. The measured average roughness values were 4, 14, 8 and $4 \mathrm{~nm}$ for the uncoated, Au-, Ag- and Al-coated samples, respectively. As seen in Fig. 1, nanocrystalline and local aggregations are observed on the surfaces of the nanothick metal layers. The Ag and Al metal layers have notably good formations. All AFM images were produced on a $4 \times 4$ $\mathrm{m}^{2}$ scale.

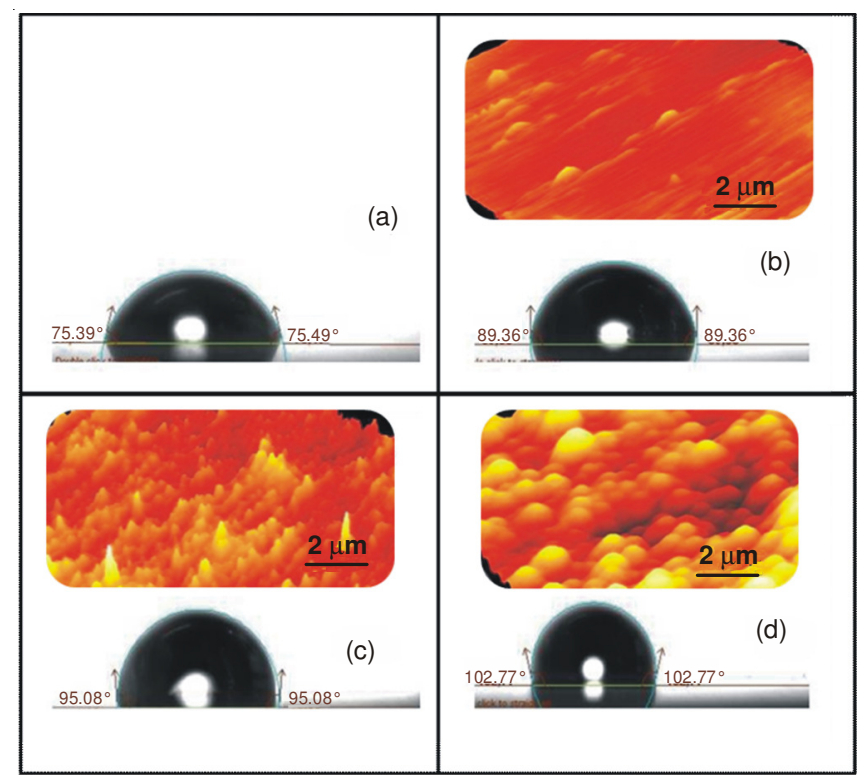

Fig. 1. 3D surface images and of the contact angle values of (a) uncoated, (b) Au-, (c) Ag-and (d) Al- coated flexible organic substrate samples, which were obtained using AFM and optical tensiometer

Theta Lite is an optical tensiometer, which can measure the contact angles of a coated surface using the sessile drop method. In this method, the Young-Laplace equation is used. The contact angle of the samples is related to the surface free energy. In the contact angle experiments, distilled water was used at room temperature. The obtained contact angles of the samples and the control sample are approximately $75^{\circ}, 90^{\circ}$, $95^{\circ}$ and $104^{\circ}$ for the uncoated, Au-, Ag- and Al-coated flexible organic substrate samples, respectively. The contact angle results are illustrated in Fig. 1. The Al coatings showed the smallest contact angle. The surface energy values of the samples were determined as $\mathrm{E}_{\text {uncoated }}>\mathrm{E}_{\mathrm{Au} \text { coated }}>\mathrm{E}_{\mathrm{Ag} \text { coated }}>$ $\mathrm{E}_{\mathrm{Al} \text { coated. }}$ According to these results, the Ag- and Al-coated flexible organic substrates are hydrophobic, the Au-coated flexible organic substrate is near hydrophobic and the uncoated flexible organic substrate is normal.

Photos of the antibacterial test procedures are provided in Fig. 2 and 2a represents the colony images of the uncoated flexible organic substrate. Images $2 \mathrm{a}, \mathrm{b}$ and $\mathrm{c}$ represent the $\mathrm{Au}-, \mathrm{Ag}-$ and Al-coated flexible organic substrates, respectively. The colony numbers of the incubated samples were determined as 125 colonies, 0 colony and 412 colonies for $\mathrm{Au} / \mathrm{FOS}, \mathrm{Ag} / \mathrm{FOS}$ and Al/FOS, respectively. The colonies of the control sample were too many to count because many colonies were grown. These results show that metal nanolayered thin films are antibacterial. These samples have 

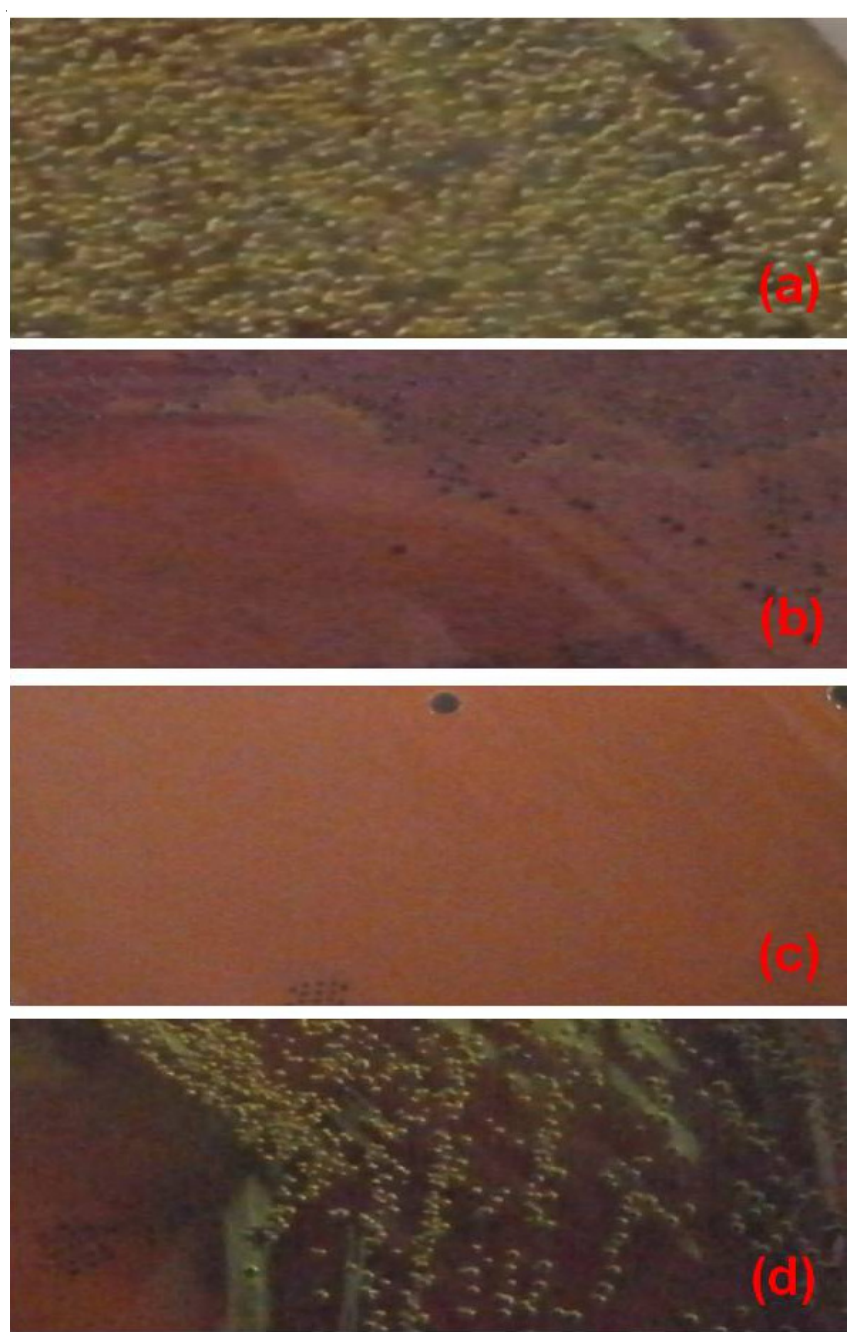

Fig. 2. Photos of the EMB agar test with E. coli after contacting the surface of the (a) uncoated, (b) Au, (c) Ag and (d) Al nano-layered coating samples

different surface properties. In particular, the surface morphologies and energies are different from one another.

The coated surfaces showed excellent antibacterial property against $E$. coli as gram-negative bacteria. The metallic silver coating showed the most efficient antibacterial properties. This result is consistent with the literature. Possible interactions that have been previously presented between silver particles and bacteria ${ }^{3,22,23}$ are summarized in 4 main groups: (a) metallic silver nanoparticles electrostatically interact with the negatively charged bacterial cell walls (b) metallic silver is incorporated into the structure of biological molecules, such as DNA and enzyme (c) the metabolic pathway is inhibited and (d) protein synthesis is inhibited.

The antibacterial properties of metallic gold have also been determined in this study. This result is consistent with the literatures ${ }^{7}$. Gold particles show the antibacterial effect in two ways $^{7}$ : (i) changing the membrane potential and inhibiting ATP syntheses and (ii) inhibiting tRNA.

Metal ions are antibacterial materials. The antibacterial effects of metal ions are related to the ionization energy. Atoms with lower ionization energy can cause faster reactions. In addition, this effect of metals strongly depends on the group number of the periodic table. Thus, aluminum metal is the lowest antibacterial material of those studied here.

\section{Conclusion}

Nano-layered $\mathrm{Au}, \mathrm{Ag}$ and $\mathrm{Al}$ films coated on flexible organic substrates using vacuum arc plasma have been successfully used for their antibacterial properties. The contact time of E. coli (ATCC 25922) to the nano-layered metal coatings is notably short. The excellent antibacterial performance of nanolayered $\mathrm{Ag}$ metal against $E$. coli was determined. In addition, other metals showed antibacterial effects compared to the uncoated control group. The antibacterial properties depend on a smooth surface. The surface free energy of the nanolayered metal coatings is also important. The antibacterial effect is dominant at lower energies. The antibacterial effect is determined as $\mathrm{Ag}>\mathrm{Au}>\mathrm{Al}$. Metal ions generally interact with bacteria. Our coated samples can be used in commercial products in biomedical fields, hospitals, electronics, medical tools, etc. The produced coatings are antibacterial and chemically inert.

\section{REFERENCES}

1. H.S. Jia, W.S. Hou, L.Q. Wei, B.S. Xu and X.G. Liu, Dent. Mater., 24, 244 (2008).

2. S.A. Kumar, Y.T. Chang, S.F. Wang and H.C. Lu, J. Phys. Chem. Solids, 71, 1484 (2010).

3. M. Guzman, J. Dille and S. Godet, Nanomed.-Nanotechnol., 8, 37 (2012).

4. K. Thongsuriwong, P. Amornpitoksuk and S. Suwanboon, Adv. Powder Technol., 24, 275 (2013).

5. H.J. Zhang and D.Z. Wen, Surf. Coat. Technol., 201, 5720 (2007).

6. H.J. Jeon, S.C. Yi and S.G. Oh, Biomaterials, 24, 4921 (2003).

7. Y. Cui, Y.Y. Zhao, Y. Tian, W. Zhang, X.Y. Lu and X.Y. Jiang, Biomaterials, 33, 2327 (2012).

8. A.M. Kraigsley and S.E. Finkel, FEMS Microbiol. Lett., 293, 135 (2009).

9. M.I. Garcia and C. LeBouguenec, Bull. I Pasteur, 94, 201 (1996).

10. T. Hamouda and J.R. Baker Jr., J. Appl. Microbiol., 89, 397 (2000).

11. D.A. Giljohann, D.S. Seferos, W.L. Daniel, M.D. Massich, P.C. Patel and C.A. Mirkin, Angew. Chem. Int. Ed., 49, 3280 (2010).

12. R.C. Jin, Angew. Chem. Int. Ed., 47, 6750 (2008).

13. N.T.K. Thanh and L.A.W. Green, Nano Today, 5, 213 (2010).

14. H.W. Gu, P.L. Ho, E. Tong, L. Wang and B. Xu, Nano Lett., 3, 1261 (2003).

15. M.Z. Balbag and S. Pat, J. Plast. Film Sheet, 27, 209 (2011).

16. M.Z. Balbag, S. Pat, M. Ozkan, N. Ekem and G. Musa, Physica B, 405, 3276 (2010).

17. M. Ozkan, N. Ekem, M.Z. Balbag, S. Pat, P I Mech. Eng. L-J. Mat., 226, 103 (2012).

18. O. Sharifahmadian, H.R. Salimijazi, M.H. Fathi, J. Mostaghimi and L. Pershin, J. Therm. Spray Technol., 22, 371 (2013).

19. M.L.W. Knetsch and L.H. Koole, Polymers-Basel, 3, 340 (2011).

20. A.J. Varkey, Sci. Res. Essays, 5, 3834 (2010).

21. I. Sondi and B. Salopek-Sondi, J. Colloid Interface Sci., 275, 177 (2004).

22. H.Q. Jiang, S. Manolache, A.C.L. Wong and F.S. Denes, J. Appl. Polym. Sci., 93, 1411 (2004).

23. E. Boisselier and D. Astruc, Chem. Soc. Rev., 38, 1759 (2009). 